\title{
Reformation and Practice of Engineering Mechanics for the Training of Outstanding Engineer
}

\author{
Yanxia Wang \\ School of Transportation and Vehicle Engineering, Shandong University of Technology, Zibo \\ 255049, china
}

wangyx200@163.com

\begin{abstract}
Keywords: Engineering mechanics; Outstanding engineers; Reformation; Practice; Educating and training
\end{abstract}

\begin{abstract}
The spirit of "Plan for Educating and Training Outstanding Engineers" is to develop students' abilities of innovation and practice. Practical ability depends on practical teaching system. The science and rationality will affect the foundation of students to practice and create. To improve the teaching effect, develop outstanding engineering talent with innovation and practical ability, a research on reformation of new practical teaching pattern has become the key part in "Plan for Educating and Training Outstanding Engineers". The course of engineering mechanics plays a connecting role between professional courses and basic course, which is a very important specialized course for outstanding engineers. There are too many concepts, theorems and formulas in this subject. In this paper, According to the cultivation of Outstanding Engineer of Mining in Shandong University of technology, the teaching process of engineering mechanics is reformed in three parts: teaching content, teaching mode and evaluation method.
\end{abstract}

\section{Introduction}

In recent 20 years, the developed countries have combined technologic tendency and science tendency into engineering education. Some colleges have already brought up the idea of "return back to engineering practice", reforming their engineering education and paying attention to the practicality and innovation to adapt to the requirement of modern grand project. By now, there are about 900 colleges that apply engineering education in America, one-third in all colleges. In Europe, such as Germany and France, a lot of famous colleges are conducting engineering education mode. Compared with developed countries, China's engineering education has a lot of problems, such as vague education goals and lack of engineering experience for teacher and training problems for students. Given in a different historical period, the purpose of engineering training could be different in China, and because of the tremendous scale, China has the unique system of the world. So there is no experience to follow and we could only find our way by innovation [1-4].

To reflect the spirit of "China medium and long term educational reform and development plan (2010-2020)", establish the idea of all-round development and diversification of talents, satisfy national strategic demand and enterprise requirements, since 2010 ministry of education approach the project of "Plan for Educating and Training Outstanding Engineers" (PETOE). This plan means to reform and develop the pattern of China engineering education, form a new pattern of personal training between colleges and enterprises, raise students' responsibility to service our country and people and, the ability to explore and solve practical problems [5-7]. In 2010, Shandong University of Technology is chosen as the first colleges for the project of PETOE. In 2013, Shandong province launched "the Experimental Specialty of Provincial Level Plan for Educating and Training Outstanding Engineers" and there are three specialties that were chosen in Shandong University of technology.

Through the communication with famed universities such as Tianjin University, Dalian University of Technology, Harbin University and Shanghai Jiao Tong University, the current practical education system has a lot of defects: the lack of connection between practical content and engineering application, deficiency of professional awareness, lack of enthusiasm of those corporation enterprises, affecting the quality of personnel training. 


\section{The Current Situation}

The Content Is Classic and Rich. The scope of engineering mechanics belongs to classical mechanics which has been developed for more than 300 years. The theory and content in this course is basically fixed and mature, leaving a familiar impression for students. Even with multiple updates the content is lack of renewal based on the emergence of new materials, new technology, and new produces. Those old knowledge does not quite fit the new situation which could reduce the enthusiasm for learning. So the problem between "old" and "new" should be deal with carefully by injecting new vitality into class. Teachers and students should work together on it.

The Engineering Background Is Clear. The topic in engineering mechanics mostly comes from actual engineering problems. Those examples and questions in current textbook have a clarity background, but usually the background is ignored and the title likely shown as "In model A---find the solution for model B". In this case, whether model A is reasonable is not considered and students only need to answer model B. Topics are generally in the same form, boring; in addition, because the topic model is unique and fixed, the answers are basically all the same, which restricts students' subjective initiatives and stops them to analyze the problem from multiple angles. It is not good for students to arouse passion and enthusiasm for learning.

Picture this; if the students are facing a realistic engineering problem, they have to finish the job from the foundation of the mechanics model to problem solving, what is need is more than theatrical knowledge; they will connect the textbook knowledge with reality. Different student according to their self-knowledge will have different answers. This will help to cultivate students' diversified engineering values and promote their recognition of courses and self-identity.

Too Much Attention to the Development of Logical Thinking. The content arrangement of the course of engineering mechanics, theoretical analysis and problem solving all show a strong logic. From the perspective of content, the course is divided into small-scale and large-scale. Small-scope: the four basic variants; according to mechanical characteristics and deformation characteristics, stress, stress and strength, deformation and stiffness conditions, the content are connected closely. Large-scale contents, according to the deformation, stress and strength, combined deformation, link with each other. Regardless of large or small scale, the knowledge in front is the base of those at the back, but relatively they are independent, self-contained also. In terms of theoretical analysis, the course is based on classical theory which is logically clear. Problem solving methods are relatively fixed; every part of the topic can be given a standardized solution mode. Such as Deformation strength, the four basic problems, following the model: "determination of which kind of deformation --dangerous surface--danger point - the calculation of stress at the danger point"; this standardized solution model shows strong logical relationship. These characteristics mentioned above could help to cultivate students' logical thinking ability. However, when it comes to practical engineering problems, engineers need more than logical thinking; it is also necessary to regard problems with dynamic developing sight, taking the spatial and temporal characteristics into account, recognizing that at the same time the solution to the same problem could be right and wrong. For example, to the same engineering problem you can treat it as a rigid model or an elastic body model, either way has its advantages and disadvantages, rationality and irrationality [8-11]. For this, the cultivation of the ability of dialectical thinking is also needed with logical thinking.

\section{Reformation and Practice}

According to the cultivation of outstanding engineer of mining in Shandong University of technology, the teaching process of engineering mechanics are reformed in three parts: teaching content, teaching mode and evaluation method.

According To the Cultivation Plan and Requirements, Adjust the Teaching System and Content. Constitute the syllabus of engineering mechanics and combine teaching content with engineering practice to establish a new mechanics system that qualifies the demand of cultivating outstanding engineering talents. 
The main content of teaching should be focused on the basic knowledge, expounding the basic concepts and theorems; combining the problems found in the process of teaching with personal experience and other people's achievement in the reformation of teaching; increasing the engineering examples. For instance, optimize the course of statics of engineering mechanics; starting from the basic concepts, gradually expand the stress analysis, simplification of force system and balance theory, from general to particular.

Using a Variety of Teaching Methods, Stimulate Students' Passion, Cultivate Students' Scientific Quality and Improve Students' Problem-Solving Ability. In the process, it is advocated that using multimedia in the teaching process, combining multimedia teaching and practicing with student teaching and practicing, flipped classroom and online learning and case studying and experiment teaching. The basic engineering mechanics concepts and the methods analyzing and solving engineering mechanics problem will be paid more attention, so that students could get a whole understanding on the main content of the course of engineering mechanics, cultivating students' ability to use knowledge to solve practical problems in reality. Students' scientific quality and ability to solve problems and team spirit also should be stressed on. Besides theoretical part, the feature of engineering mechanics, connecting with engineering practice, will be appreciated and the teaching organization pattern will be improved constantly.

Teachers ought to combine modern teaching methods with heuristic teaching method. Starting with engineering project, how to build a mechanics model should be described and at the same time guide students to think and answer after analyzing and discussing the model. And only in this way, students' modeling ability could be developed and strengthened, also with the ability to analyze and solve practical problems. Eventually students' comprehensive quality could be improved.

Lay Stress on Process Assessment and Comprehensively Assess Students' Knowledge and Skill of Engineering Mechanics. The key point of assessment is to inspect students' comprehensive ability, not just the degree of understanding of textbook knowledge. The final score consists of the daily point, midterm exam scores, final exam results and experimental scores.

\section{Summary}

The course of engineering mechanics plays a connecting role between professional courses and basic courses, which is a very important specialized course for outstanding engineers. In order to be an outstanding engineer with a solid theoretical basis and spirit of innovative and comprehensive ability, the teaching notion need to be changed by optimizing teaching system and contents, exploring new teaching methods.

\section{Acknowledgements}

This work was financially supported by the excellent course "Engineering Mechanics" of Shandong Province, a grant from National High Technology Research and Development Program of China (863 Program) (2009AA063202) and the Shandong Province Natural Science Fund (ZR2009FQ023, ZR2011EL017, ZR2013EEQ008).

\section{References}

[1] Z.J. Zhang: Analysis of the pattern of outstanding engineer cultivation at colleges, Heilongjiang Researches on Higher Education, 12 (2010) 139-141. (in Chinese)

[2] P.W. Song: Thought and Approach of Innovation Ability Cultivation for Preeminent Engineer, China Electric Power Education, 7 (2011) 25-29. (in Chinese)

[3] Z.J. Lu, H.H. Yang and Y.P. Wu: Research and Practice of Classroom Teaching Reform on Engineering Mechanics, Value Engineering, 35 (2011) 218-219. (in Chinese)

[4] W.P. Shi, C.P. Zhang and S.J. Fang: Tentative discussion on the teaching reform of engineering mechanics, Shanxi Architecture, 2 (2009) 27-29. (in Chinese) 
[5] J. Lin: Restudy on the Professional Training Program of "A Plan for Educating and Training Outstanding Engineers", Researches In Higher Education Of Engineering, 4 (2011) 11-17. (in Chinese)

[6] D.C. Li, J. Wang: Reflections on the Training of Outstanding Engineers, Education and Modernization, 3 (2011) 53-57. (in Chinese)

[7] H.J. Fu, Y. Xin: Pursuing "Engineer Excellence Program" to cultivate practical talents of technical engineering, Experimental Technology and Management, 11 (2011) 155-158. (in Chinese)

[8] Q.S. Fan: Engineering Mechanics (Higher Education Press, Beijing 2013). (In Chinese)

[9] Southwest Jiaotong University: Department of Applied Mechanics and Engineering. Engineering Mechanics Tutorial (Higher Education Press, Beijing 2013). (In Chinese)

[10]H.Z. Chan: Engineering mechanics (Higher Education Press, Beijing 2009). (In Chinese)

[11]H.W. Liu: Material Mechanics (Higher Education Press, Beijing 2011). (In Chinese) 